\title{
Desenvolvimento de ferramenta computacional para dimensionamento de seções transversais de concreto armado no estado limite último - NBR6118-2014
}

\section{Gabriel Saman D.D. Pinheiro, Luiz Carlos de Almeida}

\section{Resumo}

Em meio a uma sociedade com crescente desenvolvimento técnico-científico computacional, é um desafio desenvolver um software que facilite e replique os cálculos de dimensionamento do concreto à flexão simples, os quais vem sendo efetuados há mais de 30 anos de forma manual. $\mathrm{O}$ uso de um software para realização desses cálculos pode ser de grande auxílio nos quesitos tempo, precisão e segurança. Este projeto de iniciação científica tem como objetivo desenvolver um software na linguagem Visual Basic de forma a otimizar o processo de cálculo, evitar erros humanos e contribuir com a divulgação de conhecimento para o meio acadêmico, além de ajudar os futuros discentes cursantes da disciplina de Concreto Armado I. Foi feita inicialmente a revisão bibliográfica acerca do tema, tomando-se o cuidado de verificar todos os quatro casos possíveis de dimensionamento para a seção retangular, bem como garantir um pleno entendimento sobre cada um deles. Em seguida, foram estudadas três apostilas de Visual Basic, além da visualização de várias vídeo-aulas no canal do YouTube visualbasic.net afim de obter os conhecimentos necessários para se programar no VisualStudio 2015, software utilizado para criação do programa. Por fim, fez-se um levantamento e estudo da bibliografia referente ao MathCad 15, software que visa facilitar e verificar os cálculos a serem realizados, e então, programou-se o algoritmo para a resolução do problema em questão, aliando ele ao desenvolvimento de um design agradável e atual para o programa. Visando garantir a segurança do software, foi realizado uma bateria de testes de dimensionamento com 40 tipos diferentes de problemas.

Palavras-chave: Flexão simples; Seção retangular de concreto; VisualBasic; Concreto.

\section{Palavras-chave:}

Flexão simples; Seção retangular de concreto; VisualBasic;

\section{Introdução}

O concreto é um material de amplo uso na construção civil e constituído por aglomerante hidráulico (cimento), água, agregado graúdo (pedra britada, seixo rolado etc.) e agregado miúdo (areia e pedregulho), podendo conter adições e aditivos químicos, os quais visam melhorar ainda mais o seu desempenho (ALMEIDA, 2014, p.3).

Em meio ao avanço tecnológico da sociedade atual, cada vez mais há o surgimento de novos softwares que automatizam e solucionam problemas que antes eram feitos de forma manual. Devido à essa nova tendência tecnológica, decidiu-se pelo desenvolvimento do BeamSizer 1.0 devido ao tempo gasto para o dimensionamento manual das vigas de concreto armado ser excessivo, trabalhoso e poder conter erros humanos de cálculo. Os principais objetivos são:

1.Comparar a diferença entre o método de cálculo convencional manual (com aproximações) e o método de cálculo refinado (sem nenhuma aproximação);

2. Otimizar o tempo despendido para solucionar problemas desse tipo, visto que podem ser muito demorados se feitos de forma manual, enquanto através do programa, chega-se numa resposta mais precisa e em apenas alguns segundos;

3. Introduzir ao aluno os conhecimentos básicos inerentes à metodologia científica;

4. Desenvolvimento e aprimoramento de conhecimentos em relação à linguagem de programação Visual Basic e em relação ao software MathCad 15.

\section{Resultados e Discussão}

Comparando as duas metodologias de cálculo utilizadas no trabalho para efeitos comparativos, que são o cálculo manual e o próprio software, observa-se que a diferença na quantidade de armadura calculada sempre é inferior a $10 \%$, de forma que na maioria dos casos esta diferença é absorvida pelo arrendondamento do numero de barras utilziadas.

\section{Conclusões}

O software consegue otimizar o tempo gasto para resolução e conferência desse tipo de problema, o qual é extremamente cansativo e longo, caso feito de forma manual, além disso, dimensiona de forma mais segura pois leva em consideração todas as variáveis necessárias para o cálculo de "d", ao contrário do método manual, que faz estimativas.

\section{Agradecimentos}

Agradecimentos destinados à minha familia, pelo apoio no desenvolvimento do software, e também ao professor Dr. Luiz Carlos de Almeida, o qual sempre me orientou da melhor forma possível.

Usar esse espaço para referências, seguindo o estilo indicado - Padrão ACS ou ABNT ou Vancouver (letra Times 8). Ex:

${ }^{1}$ Curtis, M. D.; Shiu, K.; Butler, W. M. e Huffmann, J. C. J. Am. Chem. Soc. 1986, 108,3335 . 